\title{
Fulminant septic shock due to Edwardsiella tarda infection associated with multiple liver abscesses: a case report and review of the literature
}

\author{
Gultakin Hasan Bakirova ${ }^{1 *}$, Abdulrahman Alharthy', Silvia Corcione², Waleed Tharwat Aletreby', \\ Ahmed Fouad Mady ${ }^{1,3}$, Francesco Giuseppe De Rosa ${ }^{2}$ and Dimitrios Karakitsos ${ }^{1,4}$
}

\begin{abstract}
Introduction: Edwardsiella tarda uncommonly infects humans. The usual presentation is mild gastroenteritis, but systemic manifestations may occur. Lethal infections are rarely documented in patients with underlying disorders,

Case presentation: A previously healthy 37-year-old Southeast Asian woman presented to our hospital with recent onset of abdominal pain, fever, and vomiting. Her condition rapidly deteriorated with signs and symptoms of fulminant septic shock; thus, she was intubated, supported with intravenous vasopressors and fluids, and transferred to the intensive care unit. An abdominal computed tomographic scan with contrast revealed multiple liver abscesses. Blood cultures were obtained and computed tomography-guided percutaneous drainage of the liver abscesses with supplementary cultures was performed; thereafter, empirical broad-spectrum antibiotics were initiated. All cultures grew E. tarda, whereas an antibiogram showed resistance to broad-spectrum antibiotics and sensitivity to ciprofloxacin and aminoglycosides; thus, the antibiotic regimen was updated accordingly. The patient made an uneventful recovery and was discharged from the intensive care unit 14 days after admission.

Conclusion: E. tarda human infection can present as liver abscess and fulminant septic shock. E. tarda strains can be resistant to broad-spectrum antibiotics; hence, culture-based antibiotics should be used accordingly. Clinicians should be aware of this rare and potentially lethal infection.
\end{abstract}

Keywords: Case report, Edwardsiella tarda, Septic shock, Liver abscess

\section{Introduction}

Edwardsiella tarda is a gram-negative, facultative anaerobe that is a member of the family Enterobacteriaceae and was first described by Ewing et al. in 1965 [1]. Since then, a growing body of literature has reported E. tarda isolates particularly related to brackish water and marine ecosystems, including reptiles, amphibians, and fish [2]. E. tarda human infections are rare and mainly present

\footnotetext{
* Correspondence: dr.gulya07@gmail.com

${ }^{1}$ Critical Care Department, King Saud Medical City, Riyadh, Saudi Arabia

Full list of author information is available at the end of the article
}

as gastroenteritis; however, extraintestinal and systemic infections have been reported that, when present, are a potentially life-threatening condition carrying up to $50 \%$ risk of mortality [3]. Such infections include bacteremia; infections of skin, soft tissue, and biliary tract; liver and tubo-ovarian abscesses; and peritonitis, particularly in immunocompromised hosts $[4,5]$. We report a case of E. tarda infection that presented as multiple liver abscesses leading to fulminant septic shock in a previously healthy 37-year-old woman.

C C The Author(s). 2020 Open Access This article is licensed under a Creative Commons Attribution 4.0 International License, which permits use, sharing, adaptation, distribution and reproduction in any medium or format, as long as you give appropriate credit to the original author(s) and the source, provide a link to the Creative Commons licence, and indicate if changes were made. The images or other third party material in this article are included in the article's Creative Commons licence, unless indicated otherwise in a credit line to the material. If material is not included in the article's Creative Commons licence and your intended use is not permitted by statutory regulation or exceeds the permitted use, you will need to obtain permission directly from the copyright holder. To view a copy of this licence, visit http://creativecommons.org/licenses/by/4.0/ The Creative Commons Public Domain Dedication waiver (http://creativecommons.org/publicdomain/zero/1.0/) applies to the data made available in this article, unless otherwise stated in a credit line to the data. 


\section{Case presentation}

A 37-year-old Southeast Asian woman presented to the emergency department of our hospital with a 5-day history of abdominal pain, fever, and vomiting. Her past medical history was unremarkable apart from a laparoscopic cholecystectomy 10 months earlier. Upon presentation, the patient had high-grade fever, tachycardia, and hypotension suggestive of worsening sepsis, which eventually progressed rapidly to septic shock requiring high doses of noradrenaline and vasopressin. She was intubated, mechanically ventilated, and admitted to the intensive care unit (ICU) accordingly. Upon ICU admission, an abdominal computed tomographic (CT) scan with contrast (Fig. 1) revealed hypodense lesions occupying the right and left liver lobes with calcification foci suspicious of abscesses as well as mild intraabdominal free fluid collection. Initial investigations revealed a hemoglobin level of $10.4 \mathrm{~g} / \mathrm{dl}$ and a white blood cell count of $18.9 \times 10^{9} / \mathrm{L}$ with $89 \%$ neutrophils. Her platelet count was normal. Her blood urea nitrogen was raised at $12.1 \mathrm{mmol} / \mathrm{L}$ (normal range $2.5-6.4 \mathrm{mmol} / \mathrm{L}$ ), but her serum creatinine was within normal limits at $115 \mathrm{IU} / \mathrm{L}$ (normal range 71-115 IU/L). Her renal function was completely normalized following administration of intravenous fluids a few hours after ICU admission. The findings of blood film obtained for malarial parasites were negative. Notwithstanding this, liver function tests were remarkable with a total bilirubin of $25.3 \mu \mathrm{mol} / \mathrm{L}$ (direct $13.6 \mu \mathrm{mol} / \mathrm{L}$, indirect $11.7 \mu \mathrm{mol} / \mathrm{L}$ ), albumin $19.5 \mathrm{~g} / \mathrm{L}$, globulin $44.9 \mathrm{~g} / \mathrm{L}$, alkaline phosphatase $416 \mathrm{U} / \mathrm{L}$, alanine aminotransferase $549 \mathrm{IU} / \mathrm{L}$, aspartate aminotransferase $765 \mathrm{IU} / \mathrm{L}$, prothrombin time 16.5 with international normalized ratio 1.41 , activated partial thromboplastin time 39.9 seconds, and glucose 5.5 $\mathrm{mmol} / \mathrm{L}$. The patient's physical examination and chest $\mathrm{x}$ ray were unremarkable. CT-guided percutaneous

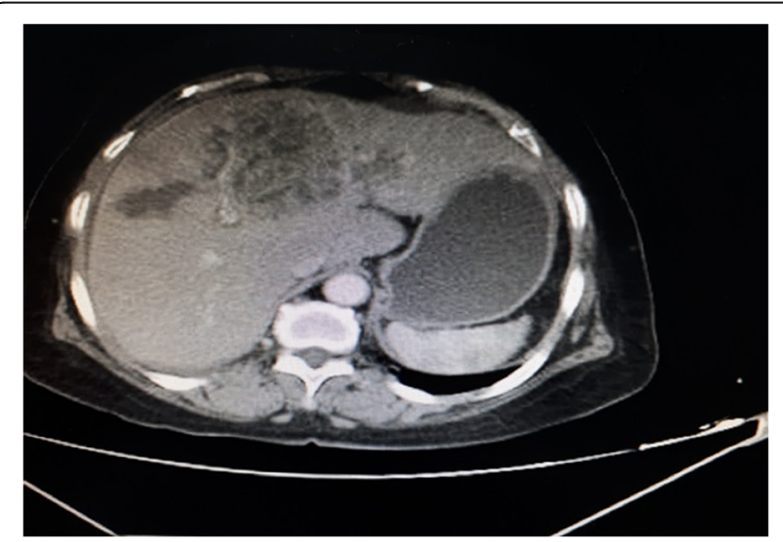

Fig. 1 Abdominal computed tomographic scan with contrast revealing liver abscesses (black arrows) due to Edwardsiella tarda infection drainage of the liver abscesses with supplementary cultures was performed while blood cultures were derived accordingly. The analysis of the fluid drained from the liver abscess showed a high white blood cell count $\left(11.8 \times 10^{3} / \mu \mathrm{l}\right)$ with polymorphic predominance $(77 \%)$ and high bilirubin and lactate dehydrogenase levels. Moreover, a gram-stained smear of the pus aspirated from the liver abscess showed few gram-negative bacilli and necrotic debris. All blood cultures as well as stool samples that were collected for 3 consecutive days grew E. tarda [6]. Specifically, blood cultures were obtained under sterile conditions and were processed using BacT/ ALERT 3D (bioMérieux, Marcy l'Etoile, France). Strains of E. tarda were identified using the MicroScan WalkAway 96si system (Siemens, Erlangen, Germany). We evaluated the drug susceptibility of the pathogen based on clinical breakpoints set by the Clinical and Laboratory Standards Institute using E-test (bioMérieux) [7].

Notably, the results of all other infectious and systemic disease workup were negative. Upon ICU admission, piperacillin-tazobactam was initiated empirically (at a dose of $4.5 \mathrm{~g}$ intravenously every 6 hours) because the results of the aforementioned cultures were not available at that time. Forty-eight hours later, due to lack of clinical improvement and worsening shock despite fluid resuscitation, antibiotics were empirically once more upgraded to meropenem ( $1 \mathrm{~g}$ every 8 hours by intravenous infusion over 3 hours) and linezolid (600 mg intravenously every 12 hours). As mentioned in the paragraphs above, all cultures grew E. tarda. The antibiogram (available when the patient had already received the upgraded antibiotics for 48 hours) showed, interestingly, that the pathogen was resistant to piperacillintazobactam and carbapenems while being sensitive to gentamicin and ciprofloxacin. Hence, the antibiotic regimen was updated to ciprofloxacin ( $400 \mathrm{mg}$ intravenously every 12 hours for 14 days) and gentamicin $(400 \mathrm{mg}$ intravenously once daily for 14 days) on the basis of the pertinent antibiogram. The clinical status of the patient gradually improved, and she was successfully weaned off vasopressors and the mechanical ventilator. She was discharged from the ICU 14 days after admission. Thereafter, she was transferred to the gastroenterology ward, where follow-up endoscopic studies revealed mild nonspecific enteritis that eventually resolved completely, and she was discharged from the hospital free of symptoms and in good health.

\section{Discussion}

E. tarda, a member of the Enterobacteriaceae family, belongs to the genus Edwardsiella along with E. hoshinae and E. ictaluri, and is a facultative anaerobic gramnegative bacillus. It has a worldwide distribution especially in water environments, whereas its role as a fish 
pathogen has long been recognized [8]. Exposure to water environments as well as aquatic animals (reptiles, snakes, turtles, and amphibians), iron overload disorders, and ingestion of contaminated raw fish were previously reported as risk factors for infection [3]. Aeromonas species, Vibrio vulnificus, and Mycobacterium marinum share the same environment and therefore a similar exposure risk to $E$. tarda; moreover, the clinical presentation of the former infections could be similar to E. tarda infections. although $M$. marinum infections tend to be generally idle and not associated with systemic manifestations [9]. Humans appear to become uncommonly infected with E. tarda. Mild gastroenteritis is the most common manifestation associated with this pathogen, but invasive enterocolitis and serious extraintestinal infections, such as necrotizing fasciitis, sepsis, wound abscess, gynecological infections, peritonitis, and osteomyelitis, have been reported in individuals with underlying systemic diseases such as malignancy, impaired immune status, diabetes mellitus, and hepatobiliary diseases [8-10]. Although gastrointestinal infections are generally self-limited [10], $E$. tarda-related septicemia mortality ranges from $38 \%$ to $50 \%$, and it should be considered a life-threatening condition $[3,11]$. This suggests that a dysfunctional intestinal barrier and/or immune system impairment related to underlying conditions might play a key role in the bacterial translocation across intestinal epithelium, which could in turn facilitate systemic dissemination [11].

We report a case of a previously healthy woman who developed liver abscesses and septic shock due to $E$. tarda infection. Although our patient had a history of cholecystectomy 10 months earlier, she did not have any history of chronic illnesses and denied any exposure to aquatic environments. All cultures that were derived prior to the empirical administration of antibiotics grew E. tarda. We are unaware whether previous cholecystectomy per se might be considered as a risk factor for developing E. tarda infection. A few case reports have outlined patients with a history of cholecystectomy and E. tarda infection, but those were also characterized by major underlying disorders $[4,11]$. Moreover, previously published articles reported E. tarda infections that presented as liver abscesses and/or bacteremia with variable modalities of management and patient outcomes [3, 5, 11-15].

In vitro studies revealed that almost all $E$. tarda isolates are susceptible to a wide range of antibacterial agents (ampicillin, most $\beta$-lactam antibiotics, quinolones, chloramphenicol, tetracycline, and aminoglycosides) that are commonly used against gram-negative bacteria [16]. In our patient's case, for the first time, to the best of our knowledge, resistance to broad-spectrum antibiotics such as carbapenems and piperacillin-tazobactam was clearly documented, whereas the E. tarda strain was susceptible to ciprofloxacin and aminoglycosides.
Our patient improved gradually during her ICU hospitalization. She finally survived despite the grave clinical presentation of the infection. Surely, our patient was immunocompetent and had no definitive risk factors for E. tarda infection, as previously discussed. Moreover, the patient was discharged from the hospital in good health. She shared her appreciation and approval regarding the received treatment and care. We speculate that her survival may be at least partially attributed to both the effective drainage of the liver abscess and the administration of culture-based specific antibiotic therapy apart from the prompt initiation of supportive ICU care. A currently growing body of literature has established $E$. tarda as an unusual cause of serious infections associated with septic shock, even in immunocompetent hosts; hence, intensivists should be aware of this potentially lethal pathogen.

\section{Conclusion}

E. tarda human infections could present as liver abscesses and fulminant septic shock even in immunocompetent patients. E. tarda strains could be resistant to broad-spectrum antibiotics; hence, culture-based antibiotics should be used accordingly. Clinicians should be aware of this rare and potentially lethal infection.

\section{Abbreviations \\ CT: Computed tomography; ICU: Intensive care unit}

\section{Authors' contributions}

GHB collected the data and drafted the manuscript. AA, SC, WTA, AFM, FGDR, and DK participated in all medical interventions, provided expert consultations regarding the care of the patient, and drafted the final version of the manuscript. All authors read and approved the final manuscript.

\section{Ethics approval and consent to participate}

Written informed consent was obtained from the patient's next-of-kin for the publication of this case report and any accompanying images. A copy of the written consent is available for review by the Editor-in-Chief of this journal.

\section{Competing interests}

The authors declare that they have no competing interests.

\section{Author details}

'Critical Care Department, King Saud Medical City, Riyadh, Saudi Arabia. ${ }^{2}$ Department of Medical Sciences, Infectious Diseases, University of Turin, Turin, Italy. ${ }^{3}$ Anesthesia Department, Faculty of Medicine, Tanta University, Tanta, Egypt. ${ }^{4}$ Department of Critical Care, Keck School of Medicine, University of Southern California, Los Angeles, CA, USA.

Received: 22 February 2020 Accepted: 27 July 2020

Published online: 09 September 2020

References

1. Ewing WH, McWhorter AC, Escobar MR, Lubin AH. Edwardsiella, a new genus of Enterobacteriaceae based on a new species, E. tarda. Int I Syst Evol Microbiol. 1965;15(1):33-8.

2. Miyazawa Y, Murakami K, Kizaki Y, Itaya Y, Takai Y, Seki H. Maternal peripartum septic shock caused by intrauterine infection with Edwardsiella tarda: a case report and review of the literature. J Obstet Gynaecol Res. 2018:44(1):171-4.

3. Hirai Y, Asahata-Tago S, Ainoda Y, Fujita T, Kikuchi K. Edwardsiella tarda bacteremia: a rare but fatal water- and foodborne infection: review of the 
literature and clinical cases from a single centre. Can J Infect Dis Med Microbiol. 2015;26(6):313-8.

4. Miyajima S, Yamakawa G, Ohana M. Edwardsiella tarda-associated cholangitis associated with Lemmel syndrome. IDCases. 2018;11:94-6.

5. Clarridge JE, Musher DM, Fainstien V, Wallace RJ. Extraintestinal human infection caused by Edwardsiella tarda. J Clin Microbiol. 1980;11:511-4.

6. Farmer JJ III, Kelly MT. Enterobacteriaceae. In: Balows A, Hausler Jr WJ, Herrmann KL, Isenberg HD, Shadomy HJ, editors. Manual of clinical microbiology. 5th ed. Washington, DC: ASM Press; 1991. p. 360-83.

7. Clinical and Laboratory Standards Institute (CLSI). Performance standards for antimicrobial susceptibility testing: twenty-third informational supplement (M100-S23). Wayne: CLSI; 2013.

8. Slaven EM, Lopez FA, Hart SM, Sanders CV. Myonecrosis caused by Edwardsiella tarda: a case report and case series of extraintestinal E. tarda infections. Clin Infect Dis. 2001;23(10):1430-3.

9. Cheung JP, Fung B, Ip WY, Chow SP. Mycobacterium marinum infection of the hand and wrist. J Orthop Surg. 2012;20(2):214-8.

10. Kamiyama S, Kuriyama A, Hashimoto T. Edwardsiella tarda bacteremia, Okayama, Japan, 2005-2016. Emerg Infect Dis. 2019;25(10):1817-23.

11. Suzuki K, Yanai M, Hayashi Y, Otsuka H, Kato K, Soma M. Edwardsiella tarda bacteremia with psoas and epidural abscess as a food-borne infection: a case report and literature review. Intern Med. 2018:57(6):893-7.

12. John AM, Prakash JA, Simon EG, Thomas N. Edwardsiella tarda sepsis with multiple liver abscesses in a patient with Cushing's syndrome. Indian J Med Microbiol. 2012;30(3):352-4.

13. Wilson JP, Waterer RR, Wofford JD, Chapman SW. Serious infections with E tarda: a case report and review of literature. Arch Intern Med. 1989;149:20810

14. Zieghelboim J, Williams TW Jr, Bradshaw MW, Harris RL. Successful medical management of a patient with multiple hepatic abscesses due to Edwardsiella tarda. Clin Infect Dis. 1992;14:117-20.

15. Koshi G, Lalitha MK. Edwardsiella tarda in a variety of human infections. Indian J Med Res. 1976;64:1753-9.

16. Stock I, Wiedemann B. Natural antibiotic susceptibilities of Edwardsiella tarda, E. ictaluri, and E. hoshinae. Antimicrob Agents Chemother. 2001;45: 2245-55.

\section{Publisher's Note}

Springer Nature remains neutral with regard to jurisdictional claims in published maps and institutional affiliations.

Ready to submit your research? Choose BMC and benefit from:

- fast, convenient online submission

- thorough peer review by experienced researchers in your field

- rapid publication on acceptance

- support for research data, including large and complex data types

- gold Open Access which fosters wider collaboration and increased citations

- maximum visibility for your research: over $100 \mathrm{M}$ website views per year

At BMC, research is always in progress.

Learn more biomedcentral.com/submissions 